\title{
Problemas para se iniciar uma aula: o que está em jogo?
}

\author{
Paulo Bareicha
}

\section{(}

Vamos jogar bola?" é uma pergunta comum de ser ouvida nas ruas e nas escolas. Bola, botão, tampinha de garrafa, qualquer coisa que lembre ou possa ser significada na categoria do futebol funciona como poderoso catalisador do imaginário e das energias individuais e grupais. Além da bola, há uma enormidade de outros jogos tradicionais, oralmente transmitidos, que alimentam e preservam a arte de brincar, de jogar, de viver com satisfação, alegria e felicidade. Algo intrínseco ao ser humano e que é mais evidente quando pensamos nos sorrisos e nas motivações juvenis: contagiantes e progressivas.

Entretanto, a realidade da maior parte dos jovens brasileiros não é regida apenas pelo signo da brincadeira e do jogo, mas, ao mesmo tempo, pelo signo da exclusão social e da violência. As palavras são diminuídas, os sonhos distorcidos, as relações mutiladas. Precocemente chegam ao banco dos réus, a uma 'justa' acusação e a uma punição. $\mathrm{Na}$ (assim considerada) melhor das hipóteses, cumprem uma medida sócio-educativa, alcançam a liberdade assistida e alimentam a pretensão de sua re-educação e re-inclusão social.

As melhores iniciativas pedagógicas foram implantadas por ONGs cujas ações incluem conteúdos e procedimentos das artes, da música, da dança, do teatro, da psicologia, da capoeira, entre outros. Em uma palavra, a melhor atenção dada a estes jovens é dada por professores de diferentes licenciaturas, instrumentalizados com métodos da pedagogia ativa. Dentro desta perspectiva, qual a dificuldade de um professor de teatro-educação para iniciar sua aula? Quais os entraves, os obstáculos, os empecilhos ao seu trabalho?

Este artigo tem como objetivo apresentar alguns resultados e apontar as principais dificuldades encontradas ao se iniciar um processo de aprendizagem através de jogos.

\section{Referencial teórico}

Nosso principal aporte teórico é a socionomia. Trata-se de uma área do conhecimento de natureza multireferencial e multiprofissional que investiga e atua nas relações interpessoais no socius. Via de regra, é incluída como disciplina na microsociologia, na psicologia social, na psicologia clínica e na pedagogia. O socionomista atua na tensão entre o indivíduo e o social. Isto significa tanto a relação da pessoa consigo mesma, como a relação entre duas pessoas, da pessoa em relação aos grupos que participa, e ainda dos

Paulo Bareicha é psicólogo e socionomista; doutorando em Teatro-Educação pela ECA-USP; professor da Faculdade de Educação da UnB; Superintendente do Instituto Círculo de Giz. 
grupos entre si. A socionomia é também caracterizada por oferecer e se interessar em desenvolver métodos de pesquisa-ação com o intuito de transformar a sociedade melhorando a qualidade da existência. Profissionais de diferentes áreas do conhecimento utilizam em sua prática com grupos a teoria-visão-de-mundo e os métodos de ação socionômicos.

Wilson Castelo de Almeida destaca a proximidade desta abordagem com a fenomenologia e o existencialismo, visto que, em pesquisaação, há uma relação direta entre os participantes do tipo sujeito-sujeito na co-construção do conhecimento - e não sujeito-objeto, como na ciência positivista; do mesmo modo, a socionomia e a fenomenologia se interessam pelos fenômenos no momento em que ocorrem. Neste sentido, devemos destacar a importância na mediação em grupos das seguintes categorias de análise: momento, corpo, intersubjetividade, construção coletiva de conhecimentos, intuição e intencionalidade (Almeida, 1988, p. 23-38).

Dentre os métodos de ação socionômicos, o mais difundido foi o psicodrama, mas em um sentido restrito à psicoterapia. Contudo, muitos são os métodos de ação: há o teatro espontâneo, o jornal vivo, os jogos dramáticos, o roleplaying, o sociodrama, o axiodrama, a psicomúsica, a psicodança, o teste sociométrico, o teste de espontaneidade, entre muitos outros. Como afirmamos em outro estudo, no campo da educação a bricolagem de conhecimentos diferentes inaugura a abordagem multireferencial que procura "tornar mais legivel a complexidade dos fenômenos que envolvem a educação, e que propóe uma leitura plural, sob diferentes pontos de vista, que implicam tanto visóes especificas, quanto linguagens apropriadas às descriçôes exigidas" (Bareicha, 1999, p. 134).

Dentro desta perspectiva multireferencial, a socionomia pode dialogar com outras metodologias do teatro-educação como o teatro foro de Augusto Boal, as peças didáticas de Bertold Brecht, o Child Drama de Peter Slade, os Jogos Teatrais de Viola Spolin, entre outros. A pre- tensão da abordagem é clara: conjugá-los sem confundi-los. Assim, a atuação multiprofissional e sua compreensão se tornam mais complexas, isto é, mais qualificadas e menos delimitadas. Institui-se um espaço aberto à pluralidade de olhares e linguagens, reconhecidos como necessários à compreensão do que é questionado, para se produzir conhecimentos atualizados e prementes.

\section{Metodologia}

Participamos de um desses programas de re-inserção social de jovens em liberdade assistida ou cumprindo medida sócio-educativa. Ele é realizado na periferia de Brasília, na cidade-satélite de Ceilândia. O nome deste bairro é emblemático tanto para a capital federal quanto para o Brasil. "CEI" significa: Campanha de Erradicação de Invasões; e "LÂNDIA", terra de. Ou seja, é a terra dos excluídos, daqueles que foram erradicados. Sua população, como a maior parte das grandes periferias brasileiras, é composta por trabalhadores que ganham muito pouco, que tiveram pouca ou nenhuma oportunidade para estudar, que vieram do norte e do nordeste em busca de melhores condições de existência. Pessoas que lutam para sobreviver e convivem com problemas infra-estruturais, com a violência e com a falta de empregos.

Nesse contexto, o Ministério da Justiça e a Secretaria de Ação Social de Brasília, bem como o Instituto de Pesquisa e Ação Modular com a colaboração do Instituto Círculo de Giz, realizam o Programa Galera Legal! São contemplados diretamente 40 jovens (dois grupos de 20), com idade entre 13 e 17 anos. Eles participam de oficinas de dança, $D J$, grafite, rap, bem como de estratégias psicopedagógicas com referencial socionômico e mediadas por metodologias do teatro-educação. Nosso principal objetivo é possibilitar novas formas de apreensão e significação das relações estabelecidas, a fim de se melhorar sua qualidade de vida, tendo como indicadores a qualidade da relação, o desempenho de papéis, a criatividade 
e a espontaneidade na construção coletiva de um sentido para a vida.

\section{Resultados}

Em nosso primeiro encontro, percebemos que uma das monitoras estava com medo. Sua função era coordenar a chamada, a entrada e saída da sala, as idas ao banheiro, a distribuição do lanche. Há mais de um ano está no lugar de quem coloca limites e aguarda angustiada a hora do enfrentamento. Nunca lhe faltaram com o respeito, mas trabalha com medo. Isso fez com que nossos primeiros contatos fossem marcados pela formalidade. Um desempenho de papéis pouco espontâneo, nada criativo, sem afetividade, mas com uma tensão fundamental que preconizava um encontro. Tínhamos um problema, não conhecíamos o grupo e eles não me conheciam; e isso me direcionou a um foco: a vinculação e a criação conjunta de regras para nossa relação.

Fui apresentado no papel de professor da Universidade, mas logo de início contei-lhes um pouco do que faço para me divertir, do meu time de futebol, do que gosto de fazer aos domingos. Sugeri que quem tivesse uma história ou caso interessante que a compartilhasse com os demais. Depois que o primeiro mostrou "o quanto era" narrando confrontos com a polícia, todos tinham algo a dizer. Posteriormente, ao repetirmos esse procedimento outras vezes, o grupo chamou este momento de "jogo do fala quem fez cabulação" - que para eles significa "coisas terríveis".

Havia desde o primeiro momento um Eu-narrador, sujeito historicamente construído, historicamente violentado, desvalorizado, discriminado, excluído. Eu-vivo ao revidar, ao realizar. Eu-em-relação-com-o-outro que desconheço, mas que percebo como diferente de mim. Alguém afirmou: "faço, por isso existo". Schiller estava correto: "só joga o homem quando é homem em todo o sentido da palavra, e é plenamente homem apenas quando joga" (apud Bally, 1973, p. 8). E estas realizações, por mais medonhas que pareçam, são próprias da humanidade. Decidi utilizar abertamente as três categorias fenomenológicas para nortear os rumos de nossa relação: a intersubjetividade, a intuição e a intencionalidade. A partir de agora, como regra, prestávamos atenção na intenção do outro, no texto coletivo produzido e nas "sacaçôes" que o grupo tinha.

Propusemos um jogo onde uma afirmação puxava a outra. Havia alguns que estavam drogados, cujo silêncio revelava a eloqüência da solidão, do sofrimento, da alienação exposta e que não deixava de provocar os demais. Transgressão e enfrentamento que poderia lhes custar o retorno imediato à prisão. Eu devia e coloquei limites. Criamos juntos uma regra: quem estivesse 'mal' sentaria na roda de cadeiras encostada na parede e os demais na roda de dentro. Sentindo-se melhor, incluía-se. Contudo, a notícia de que naquele dia não haveria lanche foi motivo de revolta. A insurreição liberava a voz, o corpo, os movimentos, as idéias, a descrença - sentimentos, idéias, vontades. O material de trabalho estava todo lá. Tive que ser ainda mais enérgico ao solicitar respeito pelo tempo que passamos juntos. Afirmamos a necessidade de se concentrarem na tarefa proposta, de tentarem se envolver com o jogo, de perceberem algum prazer ao participar. Reiniciamos e, ao se aumentar a concentração coletiva, as histórias começaram a ter segmentos engraçados, imprevisíveis e muito criativos.

Uma sucessão de surpresas tecia o texto coletivo: na semana seguinte três dos nossos jovens roubaram o equipamento da oficina de DJ e as aulas foram interrompidas pela presença de policiais, um juiz, um promotor, nenhum advogado de defesa. O espaço do jogo fora invadido. Em compensação, os personagens foram apropriados pelo grupo. Houve uma preleção sobre penas, direitos e deveres, obrigaçôes, e sobre a necessidade de se denunciar os envolvidos e recuperar o equipamento. Ele jamais foi encontrado e ninguém descobriu os responsáveis.

A visita das autoridades mudou nossa relação, para melhor. Marcou-se com clareza a 
diferença da autoridade de personagens como o policial, o juiz e o promotor, daquela do professor. Este aspecto diz respeito diretamente ao tipo de vinculação possível e ao tipo de relação que se estabelece entre jovem aluno (e não infrator) e o professor. A caracterização dos personagens foi sendo anotada e, aos poucos, construída pelo grupo. Muitos foram os aspectos negativos, mas as personagens eram valorizadas por sua instrução e pelo mérito de terem estudado tanto e chegarem aonde chegaram.

$\mathrm{Na}$ semana seguinte propusemos que ninguém dissesse nada, mas que representasse com cenas, ou com uma estátua feita com o próprio corpo, como fora sua semana. Posteriormente as estátuas ou cenas mudas puderam se mexer e completar mais expressivamente a comunicação. $\mathrm{O}$ interesse foi desperto. Apesar de curtas, as cenas trouxeram 'tribos', grupos e sua relação com 'o outro semelhante a mim'. Ao se expressarem, seus gestos eram semelhantes aos que vemos na televisão, de pessoas presas. Atos repetitivos com as mãos com indicador em riste e polegar elevado imitando-se uma arma. Gírias, palavrões, vozes altas. De pé, aos gritos, explanavam seus pontos de vista como um eloqüente político defendendo suas bases. Com o foco na intenção, o texto coletivo ia surgindo.

A dramatização espontânea permitiu que o espaço relacional fosse constituído sob o signo da brincadeira, do lúdico, do jogo. O momento do jogo durou quase cinqüenta minutos. $\mathrm{A}$ sala de aula completa foi o espaço convencionado para se jogar. Quem saísse da sala estaria fora. As estratégias dos grupos foram semelhantes: primeiro definir quem somos e o que fazemos; depois porque fazemos; posteriormente foi decidida a composição hierárquica, ou seja, quem era o chefe e quem eram os comandados; finalmente, houve um momento de confronto entre as tribos onde uma ridicularizava a outra e impunha seus valores.

Utilizamos como técnica o 'foco naquela cena' quando o barulho se tornou intenso e até cansativo. Esta preocupação foi importante porque manteve certa ordem e a noção de que as rédeas do jogo estavam sempre nas mãos dos jogadores.

Uma semana depois a aula e a vida cotidiana se misturaram novamente. $\mathrm{Na}$ noite anterior tinha havido um tiroteio e um dos nossos garotos faleceu. Outros estavam foragidos e com a prisão decretada. As queixas questionaram o limite do Programa, que não oferece profissionalização, mas apenas 'divertimento'. Mais uma vez foi necessária a afirmação do lugar da escola e de nossa proposta. Meu papel era a de um 'sustentador da crença no que fazemos'. Algum tempo depois, alguém propôs que filmássemos o que aconteceria no dia. Como aquecimento, cada um à sua vez sugeria uma frase e jogava uma bola a um companheiro, em qualquer lugar da sala, que continuaria a história. $\mathrm{O}$ jogo se tornou mais dinâmico.

Fizemos a diferenciação entre o espaço dramático das apresentaçôes, que funciona no 'como se' e o espaço da platéia, no 'como é'. Assim, preservou-se o espectador de uma ação própria da cena. Criaram histórias sobre gangues que se formaram e cometeram crimes na cidade. Lemos todas em voz alta e perguntei a eles o que poderíamos fazer agora, para dar continuidade ao nosso encontro. A sugestão escolhida foi representar uma das histórias.

A encenação começou com a interação de uma gangue em seu esconderijo. Contudo, de repente, o grupo da gangue (que estava no espaço convencionado como cênico) vai à platéia e começa a agir como se estivessem representando, mas agredindo um outro que estava assistindo. Chutes, pontapés, a briga começou. Rapidamente um tumulto generalizado. Surgiu um tipo de faca de algum lugar. Tivemos dificuldades para conter os ímpetos. $\mathrm{O}$ agredido foi embora. Os demais ficaram e explicaram o ocorrido: tinham uma pendenga a resolver e aproveitaram a oportunidade. Aí uma menina que estava na platéia disse: "mas eu e todos aqui não temos nada com isso... viemos aqui para aprender coisas e vocês vieram para cabular". Outros aderiram à afirmação, desautorizando a investida do grupo. Condenaram a iniciativa e 
recolocaram as regras grupais: "o espaço cênico é de encenação, é para fazer teatro; o espaço do grupo é de aula, para aprender coisas; se quiserem resolver suas coisas, fiquem na rua, nem venham aqui só para atrapalhar”. Entre aplausos e ovações a jovem resgatou o projeto inicial, apropriando-se dele e significando-o a seu modo. Tornou-se protagonista daqueles que já estavam se engajando nos objetivos propostos.

No último encontro do ano, a presença foi maciça. Repetimos quase todos os exercícios e jogos realizados no período, para nos lembrarmos do vivido e avaliarmos o aprendizado. Durante este aquecimento, alguém sugeriu montar um julgamento. Os papéis foram escolhidos: juiz, promotor, advogado, réu e três jurados. Como havia muitos querendo participar neste último dia, foram incluídas ainda as testemunhas da defesa e da acusação e platéia - todos participaram. Ninguém queria ser o advogado. Já os papéis de juiz e promotor precisaram ser disputados no cara ou coroa. A empolgação foi aumentando à medida que as cadeiras foram sendo dispostas como se fosse um tribunal. Foram realizados três julgamentos.

No caso em que houve a maior participação do grupo como um todo, tivemos um estupro seguido de morte. Um juiz tímido e incapaz de controlar o ímpeto da defesa e da acusação fez com que a audiência se transformasse em uma feira. Ofertas de propina, ameaças de morte e até confronto braçal entre as partes foram observadas. A platéia, procurando interagir, soprava frases propondo soluções de continuidade aos jogadores. Estes acatavam ou não, conforme julgavam necessário e coerente com a personagem que representavam. A defesa argumentou que o réu era homossexual, e que por isso não gostava de mulheres; e ainda que era doente mental e que precisava de tratamento e não de cadeia. A platéia incluía não apenas falas, como também personagens. $\mathrm{O}$ mais inusitado deles foi a própria vítima, que ressurgiu dos mortos e não deixou de atormentar o acusado até que confessou o crime. Risos por toda parte, criatividade e espontaneidade em cada quadro, funcionaram como um grupo de estudantes que construíram juntos um tipo de diversão participativa sem precedentes naquele contexto até aquele dia.

O processo pedagógico fora instaurado. Foram oito semanas. Sete encontros. A partir desse dia, as propostas de jogo se pareciam cada vez mais com o que temos nos relatos de professores no teatro-educação. Mas até aquele momento muitos foram os problemas que nos desafiaram: o medo do grupo, a insegurança quanto à técnica, a escolha da melhor estratégia, a falta de interesse do grupo, a falta de desejo do grupo, a 'vida real' que insistia em invadir a aula. Mas o grupo reagiu e verbalizou diferentes tipos de aprendizagem, agradecendo a oportunidade de participar do programa.

\section{Discussão}

Um dos maiores desafios pedagógicos da atualidade é perceber o conjunto de alunos como um grupo que possui objetivos comuns e funciona operacionalmente. Por mais 'didático' que seja o professor, o processo só se torna verdadeiramente 'vivencial' quando o aluno toma para si sua parte de responsabilidade na co-construção da educação. Isso não depende do conteúdo, senão se tomarmos a 'relação' como principal conteúdo prático a ser ensinado.

Nesse sentido, começamos juntos a construir uma relação pedagógica compreensiva e inclusiva. Isso se deu sobretudo pelo reconhecimento mútuo das diferenças e pela disponibilidade à vinculação vivida no grupo; tivemos ainda que manter cotidianamente o foco na motivação para a tarefa, retomando paulatinamente as regras co-criadas, e o estabelecimento conjunto dos objetivos de cada uma das aulas. A referência socionômica e existencial foi importante por sustentar três pressupostos decisivos para o estabelecimento de nossa relação: “(1) a pessoa é, em grande parte, resultado das relações interpessoais que estabelece durante a vida; (2) ninguém sai ileso de um encontro; e (3) o resultado qualitativo do encontro depende de 
habilidades forjadas necessariamente no espaço da convivência” (Miranda \& Miranda, 1999, p. 45).

Não podemos nos omitir do espaço de convivência, em nosso caso, a sala de aula. A princípio significada como uma pena a ser cumprida, a aula pôde ser compreendida ao final como um espaço de co-criação, de diálogo e de transformação. A diferenciação do espaço do jogo fez com que o sentido da ação pudesse ser preservado das constantes infiltraçôes, quer do desaquecimento do grupo, quer das influências do cotidiano. Do mesmo modo, a expressão no jogo diferenciou-se do espaço convencional permitindo maior liberdade de expressão e de comunicação de idéias.

Realizamos a cada dia exercícios para atores e não atores, no sentido empregado por Augusto Boal; os textos mais simples foram arrolados e posteriormente apropriados uns pelos outros; os textos se transformavam em novos textos que refletiam a trama de tudo o que o grupo viveu conjuntamente naquele período. A textualidade do real mobilizou, organizou e estruturou os alunos como um grupo operativo e produtivo. $\mathrm{O}$ jogo com as personagens ironizava e devolvia de forma espetacular ao social a violência sentida, sofrida, engolida - na falta de lanche, no roubo do aparelho de som, nas prisões, nas mortes.

Constantemente, trabalhamos na perspectiva teatral. Teatro entendido como "uma circunstância onde aparece nitidamente a tríade essencial texto, ator e público [...], sendo o teatro o produto de um processo de construção, o texto tem sido considerado como esse ponto inicial" (Ginsburg, 1997, p. 171). Mas, certamente devemos pensar esta teatralidade em um sentido mais amplo. Utilizamos o texto grupal como ponto de partida de descobertas. Passamos a repensar nossas co-criaçóes, repensando nossa relação. Permitimos a permuta entre os papéis de ator e espectador, de diretor e de protagonista. Co-desconstruimos os papéis sociais tradicionais para, experimentando-os em situação de jogo, novamente redimensioná-los na experiência cotidiana.

\section{Conclusão}

Problemas para se começar uma aula: o que está em jogo? Certamente não é a didática, a quantidade de instrumentos e objetos a serem manipulados pelo educador durante a aula. Também não é a técnica altamente destilada e, pelo mesmo motivo, desnaturada e desvinculada da realidade. Muito menos é o conteúdo, via de regra, fetichista e descontextualizado daquilo que é experimentado pela maior parte das pessoas. Não são ainda os manuais de jogos travestidos de receitas de 'como se faz', que agradam legiōes de profissionais apressados que objetivam e empobrecem o vivido. $\mathrm{O}$ que está em jogo é a relação estabelecida com cuidado, com atenção, com continência, com respeito, com mutualidade.

Estivemos diante de jovens que se apelidam pelo número da infração que cometeram; que evadiram da escola antes da quinta série; que guardam no corpo as marcas de uma juventude abreviada pelo preconceito, pela discriminação, pela falta de oportunidades; que revelam nas palavras a simplicidade, a irregularidade e a brevidade de suas simbolizações; jovens cuja brincadeira é violenta nos gestos que agridem, que invadem, que delimitam territórios, limites, espaços corporais e imaginários; jovens com potencial criativo e espontâneo para aprender a criar relaçôes mais estáveis e a construírem para si um papel social mais digno e pleno em cidadania. Estivemos bem próximos da utopia socionômica resumida na poesia Convite ao Encontro:

"Um encontro de dois: olho no olho, face a face

E quando estiveres perto arrancarei teus olhos

E os colocarei no lugar dos meus

E tu arrancarás meus olhos

E os colocará no lugar dos teus

Então eu te olharei com teus olhos

E tu me olharás com os meus"

(Jacob Levi Moreno, 1914)

Foi a crença estabelecida pela experiência do que foi vivido em comum que nos integrou 
como grupo de trabalho. Esta convicção dele derivada nos levou a compreender e a compartilhar a afirmação: "jouer, accepter le défi du jeu, c'est donc accepter se s'améliorer à travers le plaisir, ce qui fait que le théâtre est un outil fantastique dans l'education" (Brook, 1995, p. 18).

\section{Referências bibliograficas}

ALMEIDA, Wilson Castelo de. Formas do Encontro. São Paulo: Agora, 1988.

BALLY, Gustav. El juego como expresion de liberdad. México: Fondo de Cultura Económica, 1973.

BAREICHA, Paulo. Educação, teatro e psicodrama: em busca de conexões. Revista Linhas Críticas, Brasília, v. 4, n. 7-8, jul. 1998-99.

BROOK, Peter. Le téâtre, un outil fantastique pour l'education. Cahiers Pédagogiques v. 337, p. 1819, oct. 1995.

GINSBURG, Jacob. Considerações sobre a tríade essencial: texto, ator e público. Revista USP, São Paulo, v. 32, p. 170-7, dez.-fev. 1996-97.

MIRANDA, Clara; MIRANDA, Márcio. Construindo a relação de ajuda. Belo Horizonte: Editora Crescer, 1999. 